\title{
The Smart City Approach as a Response to Emerging Challenges for Urban Development
}

\author{
Marina Boykova \\ Researcher, Institute for Statistical Studies and Economics of Knowledge (ISSEK). \\ E-mail: mboykova@hse.ru \\ Irina Ilina \\ Director, Institute of Regional Studies and Urban Planning. E-mail: iilina@hse.ru
}

Mikhail Salazkin

Chief Specialist, ISSEK. E-mail: msalazkin@hse.ru

National Research University Higher School of Economics.

Address: 20 Myasnitskaya str., 101000 Moscow, Russian Federation

\begin{abstract}
$I^{n}$ light of the increasingly complex socioeconomic processes and changes, today's cities as complex systems will not be able to respond to numerous challenges unless they possess a governance model that can flexibly adjust to shifting external conditions. In this regard, there is growing demand for innovative management tools combining solutions from different fields. The 'smart city' concept is one of the most sought after. This article analyses the advantages of this concept, the necessary conditions, as well as the obstacles for implementing it. We consider the challenges related to becoming a 'smart city', the different ways a smart city comes into being, evaluate the future for smart city solutions, as well as assess the current willingness of administrations of Russian cities to adopt this model.

From our analysis, we conclude that 'smart city' strategies continue in many cases to rely on a narrow, 'technological' approach. Such an approach presupposes that the availability alone of smart infrastructure can solve

many urban problems and improve the quality of urban life. However, in contrast to the extended, comprehensive approach, it does not address many socioeconomic factors and the real needs of the population. Consequently, certain targets remain largely unfulfilled. The implementation of an integrated approach implies a number of conditions, such as the ability to integrate management decisions taken at various levels and predict how changes in one system affect other systems; a focus on interdisciplinary collaboration; and an ability to deal with resistance to changes.

A survey conducted by the HSE's Research Institute for Regional and Urban Planning in 2015 aimed to evaluate the future prospects for establishing the concept of 'smart city' in Russian cities. The survey results show that city managers in Russia in general positively perceive the 'smart city' approach as a basis for urban development strategies. Yet, the possibilities for implementing it are mostly seen as medium or long-term options.
\end{abstract}

Keywords: smart city; urban policy; complex systems management; innovation; technological approach; comprehensive approach

DOI: 10.17323/1995-459X.2016.3.65.75

Citation: Boykova M., Ilina I., Salazkin M. (2016) The Smart City Approach as a Response to Emerging Challenges for Urban Development. Foresight and STI Governance, vol. 10, no 3, pp. 65-75.

DOI: 10.17323/1995-459X.2016.3.65.75 
$\mathrm{M}$ odern cities are demonstrative reflections of diverse socioeconomic processes and changes, unparalleled in their dynamism, profoundness, and comprehensiveness. Playing increasingly significant roles in the global economy, they simultaneously face destructive ecological and social effects from their rapid growth. Of foremost importance are the goals of improving living standards, reducing social inequality, protecting the environment, and ensuring effective governance. The latter is critical because modern cities are super-complex multilevel systems consisting of numerous elements - actors who interact and cooperate with the external environment, continuously absorbing technological and other innovations. This structure will not be able to respond numerous challenges without an ongoing transformation of governance and its adaptation to changing external conditions is not envisaged [Sirkin et al., 2005]. Consequently, finding such a model becomes vital and this is a huge challenge for management teams that see a city simply as an aggregate of material infrastructure components and technology solutions with no regard for diverse social groups' interests and their interactions [Portugali, 2011].

The cognitive problem of struggling to embrace cutting-edge management models has increasing significance [Bettencourt, 2012]. Adjusting to complex systems means adopting qualitatively new standards of governance that allow technological and social aspects to be taken into account. It also means adopting new phenomena, finding a consensus between actors, and generating coordinated and effective city development strategies.

The concept of a smart city is one of such governance models and involves the active use of information and communications technology (ICT). This concept has been discussed in the scientific literature globally since the 1980s. Yet, the actual term of 'smart city' was first introduced in the early 1990s to highlight the increasing dependence of cities on technological and other innovations. A large volume of research examines issues of the 'smart' model of urbanization: its nature, opportunities, risks, and conditions for its successful implementation. An analysis of a vast range of sources shows the main advantages and limitations related to implementing such projects (Table 1).

A 'smart' model of development implies an ongoing process of innovative changes that affect all governance levels and aspects of city life. These inevitably evoke resistance from the surrounding environment in many fields, to overcome which special competences are needed. This is a lengthy process requiring considerable time and other resources to prepare for deep transformations. The process involves introducing brand new governance systems and business models, which interact with themselves and society in extraordinary ways.

We currently have a sufficient number of successful and failed projects to draw on and compile a list of strategic objectives, which provide the foundation for successfully implementing 'smart cities' [UN, 2015, 2016; Robinson, 2015]:

- a team capable of integrating management solutions at different levels and of fruitfully cooperating with the business and non-profit sector;

- an ability to maintain the focus on system interactions, their condition, and mechanisms of development, as well as to predict how changes in one system influence other systems;

\section{Table 1 . The advantages and limitations of the 'smart city' model in the context of new and existing cities}

\begin{tabular}{|c|c|c|}
\hline $\begin{array}{c}\text { Elements of } \\
\text { a 'Smart city' } \\
\text { policy }\end{array}$ & Advantages & Limitations \\
\hline $\begin{array}{l}\text { Construction } \\
\text { 'from scratch' }\end{array}$ & $\begin{array}{l}\text { - 'Smart city' implementation possible from the start, } \\
\text { clarity of aim } \\
\text { - Complex design and infrastructure creation using } \\
\text { cutting edge technologies and best city planning } \\
\text { experiences } \\
\text { - Possibility of analysing innovation business models } \\
\text { and funding alternatives } \\
\text { - Location choice based on strategic considerations } \\
\text { - Standard approaches can be replicated as a result of } \\
\text { rapid deployment and economy of scale }\end{array}$ & $\begin{array}{l}\text { - Inevitable risk of slow progress in solving problems, } \\
\text { starting from budgetary issues and lack of funding, } \\
\text { and ending in inability to attract citizens and } \\
\text { capital. Songdo in South Korea and Cyberjaya have } \\
\text { faced some of these problems } \\
\text { - Projects require great investments and tailored } \\
\text { governance models } \\
\text { - Performance-based approach could result in } \\
\text { a limited view of social value, namely social } \\
\text { cohesion and standards of living, threatening the } \\
\text { sustainable development of new cities }\end{array}$ \\
\hline $\begin{array}{l}\text { Modification of an } \\
\text { existing city }\end{array}$ & $\begin{array}{l}\text { - Urgency and relevance of cooperation between the } \\
\text { public and private sectors. Engagement of local } \\
\text { residents in developing 'smart cities' that are socially } \\
\text { sustainable and inhabitable } \\
\text { - Possibility of using crowdsourcing to speed up the } \\
\text { innovation process } \\
\text { - Stakeholders are initially identified, which allows for } \\
\text { implementing innovative methods of cooperation } \\
\text { and increases the reliability of funding } \\
\text { - Greater economic returns from projects and demand } \\
\text { for a 'smart city' }\end{array}$ & $\begin{array}{l}\text { - Tremendous efforts needed to organize and } \\
\text { discipline complex and established systems of } \\
\text { people, organizations, and other relevant actors } \\
\text { - Out-of-date infrastructure of an old city hampers } \\
\text { the implementation of a 'smart city' model } \\
\text { - Existing cities face many problems which compete } \\
\text { for a share of the city's resources. Thus, it is } \\
\text { impossible to cover all aspects of a 'smart city' - the } \\
\text { strategic objective is to correctly identify priorities. }\end{array}$ \\
\hline
\end{tabular}


- interdisciplinary interactions, assessing the effects of transformation from different viewpoints, identifying hidden opportunities, taking into account the interests of different stakeholders, and designing agreed-upon strategies for development;

- the ability to work with resistance to change;

- development of an integral, holistic decision-making approach;

- bringing together information management, information security provision, and dissemination of organizational innovations.

Addressing the aforementioned elements means that avoidable failures can be evaded and costs can be reduced when implementing a 'smart' policy. This is especially vital for developing countries that lack sufficient resources for risky experiments with urban-based innovations. Here we see a bottleneck because these countries generally have their own understanding of the concept of 'smart city' and its particular components, such as 'smart governance,' 'smart infrastructure', and 'smart energy'. This leads to a serious breakdown, which hampers the development of an effective policy. In this regard, Russia is no exception. To analyse the extent to which such principles can be adapted in Russia and taken up at a regional level, a project of the HSE's Research Institute for Regional and Urban Planning undertook an expert survey with the participation of one of the authors of this article in 2015.

\section{International experiences in implementing 'smart cities'}

By looking at international experiences of smart cities, we can identify the two most accepted urban planning approaches towards 'smart cities'- as technological and complex. Both have their own particularities, meaning, guidelines, advantages, and disadvantages. At first, the model was just a narrow technology-based approach, with ICT playing a fundamental role in all aspects of the urban economy. High-tech companies (IBM, Cisco, Google, and others) that have promoted sophisticated technologies to markets have contributed considerably to the development of this approach [Harrison et al., 2010; Paroutis et al., 2014]. However, the focus on the technological component makes it difficult to evaluate the complexity of urbanization and obtain a full understanding about the cities in which people want to live. In this approach, the goals are often confused: in practice the process of creating 'smart cities' is often limited to the modernization of infrastructure. Thus it remains unclear who the target group of this engineering infrastructure is, and whether inputs correspond to performance resulting from the functioning smart city.

With the consequences of the technology-based approach becoming clear, its limitations also appeared for European and North American experts and policy makers. First, the focus on engineering does not take into account the diversity and complexity of urban systems. Second, the technological approach works when a city is created from scratch, using a 'top down' approach, which is primarily characteristic of Asian regions. The advantage of such cases is that a city appears comprehensive from the start. Ambitious projects implemented in a new area (Masdar, Abu-Dabi and others) are naturally 'smarter', have no inherited problems, and demonstrate to the utmost degree the essence of a 'next generation city' where technological solutions are coordinated, integrated, and complementary [Siegele, 2012].

However, this model is not optimal for most European and North American countries, where cities have substantial historical and cultural backgrounds and different social contexts. In these countries, initiatives based on a complex approach are used: they are implemented using a 'bottom-up' approach in several stages, and they take into account the interests of a plurality of actors. In this case, the emphasis lies in creating human capital and aligning interdisciplinary cooperation focused on qualitative changes of the urban environment and society itself. A complex approach integrates technological and social innovations, and views a city as a 'system of systems' where the interaction of separate sub-systems is aimed at balanced development [Dirks et al., 2009; Kanter, Litow, 2009]. However, this approach also contains some pitfalls. Eager to create an ideal image of the city, as indicated by experts, there is a danger of a vast range of issues proliferating and blurring the image (what citizens should be like, socio-cultural environment, relationships between residents, etc.) [Vanolo, 2014]. A complex urban policy is effective if it develops out of discussions with a wide range of actors and contains well-articulated priorities.

Only when all possible aspects are considered systematically can a 'smart city' hope to rise to a new level. Previous initiatives were not coordinated. Recently, the United Nations (UN) and the International Telecommunication Union (ITU) have tried to systematize the process on a global scale. We note the array of international studies, methodological manuals, standards, and effectiveness indicators, which are being developed to assess the progress of cities in implementing 'smart' policies. The indicators correspond to the objectives of sustainable development as stated by the UN in 2015 [UN, 2015]. Cities such as Dubai, Montevideo, Buenos Aires, Singapore, and others already use these indicators in their strategic governance. Besides, the so-called Rome Declaration ${ }^{1}$ has been drawn up and states the priorities that should be the basis of all policies to transition to a 'smart' model [UNECE, ITU, 2016]:

\footnotetext{
${ }^{1}$ Ratified at the Forum session 'Shaping Smarter and More Sustainable Cities: Striving for Sustainable Development Goals', which took place on May 19, 2016 in Rome (Italy) and was organized by the United Nations Economic Commission for Europe, UNECE and the International Telecommunication Union.
} 
- to be guided by the above-mentioned effectiveness indicators when designing national and local legislation, standards and development plans, and when assessing cities' performance in seeking 'smart' and 'sustainable' status;

- to encourage adherence to international standards regarding the 'Internet of Things', which 'smart technologies' are mainly based on;

- to mobilize the use of expert resources and knowledge exchange to develop international, national, and regional cooperation;

- to develop 'smart' governance to provide a constructive dialogue between authorities and residents, combining both 'top-down' and 'bottom-up' initiatives;

- to balance the 'smart city' status criteria and progress indicators offered by different stakeholders and design a global index of 'smart cities';

- to develop a global platform for stakeholder dialogue and exchange of experiences;

- to encourage 'smart cities' pilot projects and flagship initiatives.

The basic principles as set out by the UN Commission on Science and Technology for Development regarding 'smart' infrastructure design projects also deserve attention [UN, 2016]:

- Focus of 'smart' infrastructure on the local population's demands and inclusiveness: Development should be based on a people-centric approach rather than on a 'technological' one. The order of priorities and accountability should be adhered to: living standards $->$ state of the urban environment -> technological solutions. Local residents' lifestyles, culture, behaviour, and needs should be taken into consideration, and can vary widely across countries and geographical regions; hence, the need for local adaptations of 'smart' solutions;

- Interoperability and flexibility: All infrastructure elements should be interchangeable, regulated according to certain standards, and able to be modified and improved;

- Risk management and safety: Infrastructure design should be based on a state-of-the-art risk management system, risk minimization policies, and adaptation to dynamic development under conditions of external shocks.

\section{Policy challenges and resources}

Generalizing from various cases of 'smart cities' permits us to draw up several success formulas and the reasons for failed initiatives. Policy makers face the problem of learning from and adapting existing experiences and innovative initiatives (technological, managerial, organizational and social) to find solutions to urban problems and to ensure dynamic development [Robinson, 2015]. We now outline the conditions that should be factored in when planning 'smart' policies.

\section{Education and exchange of experiences}

It is commonly believed that a 'smart' model is a risky initiative because of a lack of evidence in its favour. However, there are more than enough qualitative cases testifying to its effectiveness and substantial contributions towards new standards of development.

Progress towards 'smart' development has all the features of an innovative project. That is why a city in every single case is regarded as an experimental platform. The problem is that local governments have no experience in financing and implementing innovative business models that are able to convert existing finance schemes to successful results. Skilled work with large datasets and correct interpretation make it possible to reduce the number of mistakes and design a policy that is adapted as far as possible to existing and potential resources. 'Smart city' governance has no need for universal and all-encompassing management. Of course, a set of basic recommendations and principles exists but detailed instructions depend on the specificities of concrete areas and the available resources.

A widespread barrier for implementing 'smart' solutions is the concern about the lack of practical pilots. A special initiative aiming to overcome this problem with regard to testing 'intellectual' urban technologies is being implemented in the United States. The US-based Pegasus Holdings, a private company, is constructing a model, uninhabited city called City Labs in the desert of New Mexico, equipped with all the necessary infrastructure. It was conceived as a testing area for scientific experiments and for developing innovative solutions. City Labs is considered an ideal platform for testing the latest technologies intended for use in megalopolises in a convenient and safe environment. In particular, Pegasus Holdings intends to test intellectual road traffic monitoring systems, 'smart' electrical grids, energy-efficient technologies, and new generation wireless communications. For example, special computer programs facilitating the management of residential energy and water consumption will simulate virtual citizens' behaviour. The compatibility of disruptive technologies and existing municipal and other infrastructure will be tested in the same way [Monks, 2015].

\section{Cooperation and governance}

'Smart' city development is not fostered exclusively by top-down or bottom-up initiatives. The two drivers are engaged in the process simultaneously. Thus an 'integrator-coordinator' who can combine the 
available resources at the right time, place and in the required combination is needed. The availability of such a capability has great weight when making investment decisions. Goods and technology producers, service providers, and funding organizations are generally interested in the initiatives of cities where the local administrations have succeeded in creating the most advantageous conditions for such projects.

The 'Smart city' model provides for the systematic flow of innovations that become possible due to the available technologies. At the same time, however, the interactions between the processes that consume resources and those that create economic and social value change. Within this conceptual framework, a vision that is shared by the city's stakeholders is formed, and its implementation is encouraged by active cooperation between them.

Federal governments have a substantial role in disseminating the 'smart' city model dissemination, in particular the model of intellectual services. Federal governments should cooperate with city administrations, businesses, and scientists to assess the potential advantages of introducing 'smart' solutions. Departments responsible for various municipal services should share this vision and have a roadmap for implementing it. Thus, the relevant actors will be able to get a clear idea about the current situation in the 'smart cities' market and the expected results, and fragmentation can be avoided. In Great Britain, for example, the Future City Catapult initiative is being implemented to coordinate stakeholders' actions and design a coordinated development strategy [BIS, 2013].

\section{Interdisciplinary collaboration}

The complex nature of 'smart' initiatives implies interdisciplinary collaboration involving experts in architecture, economics, social sciences, psychology, systems analysis, process engineering, and others. There is a large-scale challenge here connected with the need to overcome experts' narrow disciplinary mentality and to develop their readiness to take into account an 'external' viewpoint [Robinson, 2015]. Introducing 'smart' solutions requires a cross-sectoral managerial approach. Spheres of municipal services such as energy grids, water supply, recycling, transport, and healthcare are dealt with and managed separately, hence limiting the potential opportunities for stakeholders. A cross-sectoral approach makes it possible to overcome this tendency [BIS, 2013]. However, the need for an interdisciplinary transition is a complex challenge. It requires specialists who are capable of moving beyond the bounds of narrow professional thinking, have at least some basic awareness of related disciplines, and possess multi-level process design skills.

\section{Overcoming cognitive traps}

Governing cities as complex systems involves dealing with two types of difficulties: technological [Singh, 1997] and cognitive [Burleson, Caplan, 1998]. Cognitive difficulties are created by the huge number of diverse and intangible social and other drivers, which have indirect and dynamic linkages. In this instance, there is a temptation to choose a narrow approach focused on infrastructural high-tech solutions, which does not in most cases satisfy the local population's demands and does not improve living standards.

In contrast, cognitive 'plasticity' or compliance takes into consideration the social aspects and human capital and hence, allows for a more comprehensive and integrated approach. Being able to manage cognitive complexity is an increasingly urgent task. One of the most effective tools to do this is visualization, which clearly shows the non-linear interactions of different systems without any loss of essential information [Tufte, 2001; Keller et al., 2006; and others]. For example, quality function deployment, $\mathrm{QFD}^{2}$ [Hunt, Xavier, 2003; and others] is based on visualization and provides for an adequate 'transition' of stakeholders' demands into development strategies. QFD and similar tools are based on scientific methods of data collection and processing, enable productive interactions between experts, mobilize intellectual capital, and make effective knowledge management possible [Khromov-Borisov, 2011]. These tools help to 'decipher' the true demands of any urban stakeholders and to design methods for satisfying these demands as best as possible.

\section{The market of solutions for 'smart cities'}

The UK's Department for Business, Innovation and Skills (BIS) conducted a study of the intellectual technologies market for five key sectors of municipal services: water supply, recycling, energy grids, transport, and healthcare services [BIS, 2013]. This market has tremendous potential. Solutions implemented on this market can become a catalyst for the further development of existing designing and engineering services and the creation of new services. According to a forecast by BIS, the size of the aforementioned market will be USD 408 billion by 2020. In particular, by 2018 the market turnover will be USD 4.5 billion for digital infrastructure-based 'smart' transport services. These designs, in turn, will be the basis for other solutions meant for a larger market valued at about USD 100 billion in, for example, parking management, urban navigation, and road traffic. The development of services such

\footnotetext{
${ }^{2}$ The method of QFD was proposed in Japan in the early 1960s. The conventional abbreviation QFD is usually used in the literature, although the term 'consumer quality management' is a more accurate definition reflecting the meaning of this method.
} 
as highway design and big data processing is also planned. The introduction of 'smart' solutions makes for better optimization of resources, more effective municipal sector management, longer service life of infrastructure, and lower costs.

The confusion between the notions smart city solutions and future city solutions is a barrier for market development. The latter mean innovation projects focused mainly on the low carbon economy. In turn, 'smart city' designs mean digital technologies applied to address social, ecological, and economic issues. They can be based solely on digital infrastructure or in combination with material infrastructure; however, in the latter case, actors have no clear understanding of the sources of investment payback. Implementing 'smart' solutions and profit maximization demand a large-scale reorganization of existing operational and managerial processes. They are impossible without effective collaboration between companies in the value chain. Otherwise, it is very difficult for the companies to introduce disruptive technologies because they lack a comprehensive vision of the positive consequences of intellectual design. 'Smart' technologies help to optimize resource consumption, improve service quality due to skillful management of supply and demand, and save substantial amount of funds. For example, using 'smart' technologies in the water sector can save between USD 7.1 and 12.5 billion annually according to different assessments [BIS, 2013]. Today, only through combined efforts can urban stakeholders develop a 'smart' solutions market to satisfy all their needs. As digital technologies are rapidly getting cheaper, the dynamics of the market will help these technologies to penetrate more, which in turn will make all areas of municipal services more effective. Energy, mobility, management and other intellectual systems are already being implemented in 'smart cities' by creating official support channels and mechanisms.

The research and consulting organization Frost \& Sullivan has estimated the overall market potential of 'smart cities' at USD 1.5 trillion by 2020 [Frost \& Sullivan, 2014]. They include energy grids, transport, healthcare, construction, infrastructure, and governance. Nevertheless, raising funds and designing relevant business models remain on the agenda because many cities around the world lack sufficient resources. Four business models exist to help companies effectively cooperate with municipal authorities and services [Singh, 2014]:

- 'Build - Own - Operate';

- 'Build - Operate - Transfer';

- 'Build - Operate - Manage';

- Open Business Model.

The Open Business Model stimulates innovation the most, which is explained by the high level of flexibility and scalability the model gives. It is expected that actors will perform one or more of the following functions in the given market:

- system integration ('door-to-door' service);

- network operation (communication providers);

- supply of equipment and software products;

- service supply management.

In particular, 'smart cities' have become a strong driver of demand for energy grids, which involve diverse sources and are equipped with energy accumulation systems, and of demand for the corresponding intellectual devices. It is expected that the size of this market will exceed USD 1 trillion by 2019 [Frost \& Sullivan, 2014], a 22\% increase compared to today's figures [Markets and Markets, 2016]. However, the requirements for the accumulative capabilities and the ecological standards of energy systems are becoming stricter. 'Smart' solutions are offered for high-tech industries, buildings, transport, and management of utilities and safety, providing maximum amounts of information and easier data access.

The 'smart cities' market stimulates the search for innovative solutions that can solve the challenges of urbanization, provide feedback from users, and improve the dialogue between citizens and service suppliers. A diversity of infrastructure, digital technologies, social capital (including local competences) need to be activated when developing the 'smart cities' market. Substantial growth of this market is expected in the most developed countries in the world. Forecasts indicate that the market will be shaped by the latest wireless networks and computerization technologies such as Z-Wave, Insteon, and others [BIS, 2013].

\section{Prospects for the transition to a 'smart' model in Russian cities}

In recent years, Russia has seen growing interest in the idea of 'smart cities'. Pilot projects are currently being implemented in Ekaterinburg, Samara, Armavir, and other cities. The city of Moscow operates a web portal for state and municipal services, a unified medical data analytical system, and other similar initiatives. Nevertheless, we still do not observe a comprehensive understanding of the concept of 'smart city'. Some organizations have attempted to offer their own vision of the term, which appears to be based on a narrow technological approach and the specific character of their activities. Essentially, they focus on the 'energy' elements of 'smart' infrastructure, which provide for the construction of safe, effective, and sustainable systems of energy production, supply, and consumption [Tsymbal, Koptelov, 2010]. 
The results of a study conducted in 2015 by the HSE's Research Institute for Regional and Urban Planning illustrate the perceptions of the 'smart city' concept among municipal authorities, as well as the barriers to the wider dissemination of the concept in Russia.

\section{Survey methodology and sampling description}

When drawing up the sample, the survey aimed to use a comprehensive approach when analysing the problems faced by Russian cities of different types, and to select suitable development models. The main sampling criteria of cities in which to carry out the survey were as follows:

- size - megalopolises, large cities, medium-sized towns and small towns (Table 2);

- contribution to federal and regional budget - donor or recipient cities;

- policy approach - conservative or liberal;

- location - variety of regions of Russia;

- diversity of sector specialization, including science cities and monocities.

46 respondents from 23 cities and towns took part in the survey, representing the following social groups:

- authorities (mayors, ministers, and heads of municipal administrations);

- business (managers of backbone enterprises and investors);

- science (urbanists, city planners);

- expert community;

- public.

Theorists, practical workers, and specialists in municipal management were represented in the sampling. Practical workers formed the majority of the sample: $60 \%$ of respondents had a direct relationship to the administration of urban territories. More than $90 \%$ had worked in this sphere for more than ten years, while only $3 \%$ had been working in that area for less than one year. Respondents' average age was 45 years. All participants of the survey had completed higher education, with more than $30 \%$ possessing a PhD degree (either candidate or full doctor as per the Russian system of doctorates).

Initially, we conducted a questionnaire survey. We then followed up the questionnaire with semistructured interviews. The questions in the questionnaire and the formalized part of the interview were identical. There questionnaire contained 14 questions about the most important urban problems and their causes, including:

- evaluation of the state of the principal elements of urban infrastructure;

- choice of main areas and priorities of urban development, the influence of external factors and changing socioeconomic conditions;

- effectiveness of state and municipal administration and its influence on the scope for urban development;

- role of strategic planning and the introduction of new urbanization models (with an emphasis on the idea of 'smart city');

- engagement of the local population in decision making.

The survey paid special attention to the state of infrastructure because it determines the quality of the urban environment and influences competitiveness, it is also focused on the prospects of using innovative technologies.

\section{Evaluation of current urban development problems}

The initial questionnaire survey revealed that local authorities were interested in the development of public infrastructure and in creating the necessary conditions. Respondents cited the following as the critical obstacles for urban development:

- problems with the tax system;

- frequent changes in the legislation;

- lack of qualified and motivated personnel and competent managers;

- difficulties in getting financial credit;

- weak support from regional and federal authorities.

Table 2. Distribution of cities by category in the sample

\begin{tabular}{|l|c|c|c|}
\hline Category & Population (thousands of people) & Number of cities in the sample & Share in the sample (\%) \\
\hline Largest & Over 1000 & 3 & 13.1 \\
\hline Large & $500-1000$ & 1 & 4.3 \\
\hline Big & $100-500$ & 14 & 60.9 \\
\hline Medium & $50-100$ & 1 & 4.3 \\
\hline Small & Less than 50 & 4 & 17.4 \\
\hline \multicolumn{4}{l}{ Source: compiled by the authors. } \\
\hline
\end{tabular}


Figure 1. Evaluations of the importance of different factors as sources of urban development problems (share of respondents who selected each answer out of the total number of respondents, $\%)^{\star}$

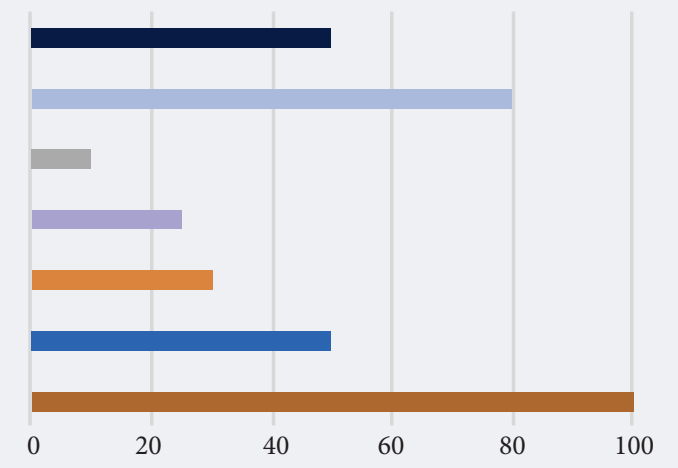

* The sum exceeds $100 \%$ as respondents could choose several answers. Source: compiled by authors based on the survey results.
- Construction of affordable accommodation and development of the rental housing sector

- Deterioration of physical and non-economic assets - machinery, municipal equipment, urban infrastructure facilities, and production assets of backbone enterprises

- Inadequate transport infrastructure

- Adverse demographic situation

High social costs in the municipal budget connected with supporting a necessary level of social infrastructure

- High rates for municipal services and their regulation

- Support for entrepreneurship and business development infrastructure at the municipal level

The survey results allow us to conclude that in recent years, municipal authorities have become considerably less motivated to modernize the territories for which they are responsible. The reasons for this are primarily caused by the existing system of inter-budgetary relations and the tax system. Respondents perceived the support mechanisms from regional and federal authorities as ineffective.

Based on the questionnaire survey results, we were able to test some suggested trends in urban development and formulate the following additional hypotheses:

- in decision making, short-term interests predominate;

- there is no comprehensive idea about the effects of transitioning to new development models;

- there are unclear barriers for introducing innovations.

By analysing the questionnaires, we were able to expand the list of questions for the follow-up in-depth interviews. Additional questions asked respondents to objectively assess urban problems and took account of each respondent's area of expertise. They concerned the design of strategic plans and new city development models, their understanding of the principles of 'smart' development, their attitudes towards the idea of 'smart city', and the possibilities of introducing intellectual technologies. In many cases, the focus was on the challenges for a specific city or sector. The questions and answers were divided into four blocks:

- city development problems;

- specificities of developing public infrastructure;

- effectiveness of state institutions of urban development management;

- opportunities for implementing a 'smart' model in Russian cities and towns.

The answers varied depending on the size of the city that the respondents represented. It was striking that the expert assessments given during the interviews differed to those presented in the questionnaires. During the interviews, the reasons for the urban development problems and their possible solutions were discussed (Figure 1). The most important negative factor cited by the respondents was the lack of principles and tools for managing public funds to link spending of budget funds with concrete, measurable, and socially significant results. Introducing medium-term budget planning, result-oriented budgeting, and risk management were included in the list of the main areas for reform. Respondents noted the absence of opportunities for non-standard decision making, which is conditioned by the current legislation on municipal assets management (real estate, land, loans, property laws, etc.)

Figure 1 shows the prevalence of two factors hampering the transition to a 'smart city' model: a lack of business support and the deterioration of physical and non-economic assets.

Respondents also noted weak civic engagement; a low interest among educated and active people in settling down in a town. Respondents from small and medium-sized towns are more concerned about retaining human capital in the existing conditions. For the larger towns, the more pressing issue is how to provide a good quality of life to different social groups with varying income levels.

A significant problem for business is the weak support from federal and regional authorities. A big driver for 'smart' model urban development could be radically upgrading infrastructure. However, municipal representatives said that they are focused only on repairing existing communications and see the opportunilities for modernization in the contemporary high-tech sphere.

In terms of future planning, the views of all respondents on the key issues of urban socioeconomic development strategy largely coincided. There was a general understanding about the need for balanced 


\section{Table 3. Respondents' assessments of how serious a problem different types of municipal public infrastructure are, and their influence on the attractiveness of urban territories (towns) for business and population}

\begin{tabular}{|l|c|c|}
\hline \multicolumn{1}{|c|}{ Type of infrastructure } & $\begin{array}{c}\text { Place in problem } \\
\text { urgency rating }\end{array}$ & $\begin{array}{c}\text { Influence on city's } \\
\text { attractiveness for business and } \\
\text { population }\end{array}$ \\
\hline Housing utilities & 1 & High \\
\hline Transport & 2 & Moderate \\
\hline $\begin{array}{l}\text { Governance, communications, and information systems as well as other } \\
\text { municipal service organizations }\end{array}$ & 3 & Moderate \\
\hline Social infrastructure (education, healthcare, culture, sport, social services) & 4 & High \\
\hline Consumer market (trade, public catering, public services for population) & 5 & Moderate \\
\hline Public security on the territory of municipality & - & Low \\
\hline Source: compiled by authors based on the survey results. & & \multicolumn{1}{|c|}{} \\
\hline
\end{tabular}

development. However, the overwhelming majority of respondents (90\%) felt that the real contribution to modernization of the strategies under development was extremely low. In all cases, the reasons were related to methodological problems, a formal approach to strategic planning, the absence of implementation mechanisms, and a lack of financial support.

Table 3 shows the distribution of answers to the question about the type of urban infrastructure that most influences the outflow of resources and influences how much investment a town can attract. The indisputable leader in both dimensions is housing utilities, although transport and social infrastructure are also rated highly.

The majority of respondents responded positively about the rationale for active civic engagement in decision making on improving the urban environment. In turn, assessments of the effectiveness of policy mechanisms for problem solving were more diverse. Respondents perceived state and business financial support as playing a critical role. Organizational and some other aspects were seen as making only moderate contributions, while social mechanisms, external factors, and market conditions were felt to have the least significant influence.

\section{Respondents' ideas about the 'smart' model}

For the present article, we paid particular attention to the answers of the survey questions about the prospects of introducing innovative development models in Russian towns. According to the survey, all respondents are aware of the idea of a 'smart model' and its advantages. Respondents were offered to choose one of three definitions, which best corresponds to their idea of the meaning of this model (Table 4).

More than two thirds of the survey participants are well aware of the 'smart city' model; approximately $50 \%$ of them have a certain position on it. Roughly $72 \%$ of respondents have received various suggestions for how to introduce intellectual technologies in the territories for which they are responsible.

The majority expressed a positive attitude toward the discussed concept. Only 10\% were critical, even going as far as to totally reject it. Nevertheless, only one respondent stated that he was fully ready now to look at implementing it in his town. Nearly $80 \%$ felt that the 'smart city' model could be introduced in the long-term (ten or more years). According to $50 \%$ of respondents, it is possible to implement the concept in Russia now but only in the largest cities, which have significant resources. Moscow (90\%) and Kazan (10\%) were most often mentioned as examples of such cities. Other opinions stated that the concept would be effective if implemented when constructing new towns from 'scratch' ( $91 \%$ of respondents) or when transforming science cities and Arctic towns (41 and 39\% respectively).

\section{Table 4. Respondents' interpretations about the notion of 'smart city'}

\begin{tabular}{|l|c|}
\hline \multicolumn{1}{|c|}{ 'Smart city' concept meaning - different definitions } & $\begin{array}{c}\text { Share of respondents who } \\
\text { selected each answer (\%) }\end{array}$ \\
\hline $\begin{array}{l}\text { Information and ICT use as part of the functioning of individual systems of } \\
\text { municipal facilities }\end{array}$ & 17.4 \\
\hline Integrated innovative urban governance of social life with the use of ICT & 60.9 \\
\hline $\begin{array}{l}\text { Strategic management aimed at creating the conditions for developing human } \\
\text { potential and providing sustainable development based on ICT and other } \\
\text { innovative technologies }\end{array}$ & 21.7 \\
\hline Source: compiled by authors based on the survey results. & \\
\hline
\end{tabular}


Table 5. City infrastructure sectors ranked according to their potential to introduce intellectual technologies in the short-term

\begin{tabular}{|l|l|c|}
\hline \multicolumn{1}{|c|}{ № } & \multicolumn{1}{|c|}{ Sector name } & Assessment of potential \\
\hline 1 & Energy supply & Very high \\
\hline 2 & Heat supply & High \\
\hline 3 & Water supply & High \\
\hline 4 & Transport & Moderate \\
\hline 5 & Residential construction and civil engineering & Low \\
\hline 6 & Consumer market (trade, public catering, public services for population) & Low \\
\hline 7 & Public security & Very high \\
\hline 8 & Ecological safety & Low \\
\hline 9 & Governance, communications, and information systems, and other municipal service organizations & High \\
\hline 10 & Social infrastructure (education, healthcare, culture, sports, social services) & Moderate \\
\hline 11 & Municipal governance & High \\
\hline Source: compiled by authors based on the survey results. & \\
\hline
\end{tabular}

Finally, respondents were asked about how ready they thought different municipal service sectors were for implementing 'smart' technologies (Table 5). Sectors such as energy grids, public safety, heat and water supply, information systems, and municipal governance got the highest ratings.

Overall, our survey results highlight that despite understanding the obvious advantages of a 'smart city' model, municipal managers still largely view it as an expensive and exclusive 'toy'. Moreover, the potential effects of a 'smart city' model such as a more rational use of resources, sustainable development, and better living standards remain at the periphery of their priorities. The community of urban managers is mostly not ready to implement innovative city development models, including a 'smart' one. However, we may still see positive changes in the future. It is necessary to transform the concept of 'smart city' into a clear managerial model adapted to the national context, and disseminate it widely.

\section{Conclusion}

On territories that have been urbanized according to the 'smart city' model, there are significant opportunities for economic growth, greater productivity and employment, as well as a whole range of other positive effects. Assimilating this concept is a serious managerial challenge and a long process that requires numerous bottlenecks to be overcome. Irrespective of whether the transition to a 'smart city' model means transforming an existing town or creating one from scratch, material and non-material resources need to be invested: in particular, the availability of human capital with special qualifications is required.

Analysing current global experiences has enabled us to formulate a set of principles for 'smart' development. These principles can help ensure the success of similar initiatives and avoid significant losses in resources. This is especially relevant for Russia and other countries, including developing countries.

In this article, we analysed the main challenges related to a transition to a 'smart' model and how this transition is implemented. We also evaluated the market prospects of the relevant technologies, how ready Russian cities are for such a model, and the obstacles standing in the way of such a transition.

At the present time, the 'smart city' model is moving into a new evolutionary stage, with efforts to design unified managerial principles for developing relevant strategies and indicators to evaluate their effectiveness. The 2016 Rome Declaration formulated a set of priorities that should form the core of local urban development programmes.

In Russia, this process is in its nascent stage. Different players have their own interpretations about the substance of the 'smart city' concept based on their current activity. As a rule, they are limited to a narrow technological viewpoint of the situation. They are primarily focused on modernization of utilities and increasing energy efficiency.

Survey results conducted by the HSE's Research Institute for Regional and Urban Planning in 2015 revealed a more detailed picture of the perceptions of municipal authorities and other actors about the concept of 'smart city' and the barriers hampering its implementation in the Russian context. As shown by the survey, city decision makers positively perceive the idea of 'smart city' overall yet see the possibility of implementing such an idea mainly in the medium or long-term. universities of the Russian Federation in the programme '5-100'. 


\section{References}

Alawadhi S., Aldama-Nalda A., Chourabi H., Pardo T.A., Gil-Garcia R.J., Mellouli S., Scholl H.J., Nam T., Walker S. (2012) Smart cities and service integration initiatives in North American cities: A status report. Proceedings of the 13th Annual International Conference on Digital Government Research, New York: Association for Computing Machinery, pp. 289-290.

Baccarne B., Schuurman D., Mechant P., De Marez L. (2014) The Role of Urban Living Labs in a Smart City. Paper presented at the XXV ISPIM Conference - Innovation for Sustainable Economy \& Society, 8-11 June 2014, Dublin, Ireland.

Bakici T., Almirall E., Wareham J. (2013) A Smart City Initiative: The Case of Barcelona Tuba. Journal of the Knowledge Economy, vol. 4, no 2, pp. 135-148.

Belissent J. (2011) Smart City Leaders Need Better Governance Tools: Smart City Governance Brings New Opportunities for Tech Providers, Cambridge, MA: Forrester Research.

Bettencourt L. (2012) Origins of Scaling in Cities (SFI Working Paper), Santa-Fe: Santa-Fe Institute.

BIS (2013) The Smart City Market: Opportunities for the UK (BIS Research Paper no 13), London: Department for Business, Innovation and Skills.

Bria F. (2014) Digital Social Innovation Interim Report, London: NESTA.

Brooker D. (2012) 'Build it and they will come'? A critical examination of utopian planning practices and their socio-spatial impacts in Malaysia’s intelligent city. Asian Geographer, vol. 29, no 1, pp. 39-56.

Burleson B.R., Caplan S.E. (1998) Cognitive complexity. Communication and personality: Trait perspectives (eds. J.C. McCroskey, J.A. Daly, M.M. Martin, M.J. Beatty), Creskill, NJ: Hampton Press, pp. 233-286

Dirks S., Keeling M., Dencik J. (2009) How Smart is Your City?: Helping Cities Measure Progress, Somers, NY: IBM Global Business Services.

Frost\&Sullivan (2014) Strategic Opportunity Analysis of the Global Smart City Market. Smart City Market is Likely to be Worth a Cumulative $\$ 1.565$ Trillion by 2020, Frost\&Sullivan.

Garner C., Dornan A. (2011) How can knowledge cities become smart? Proceedings of the 4th Knowledge Cities World Summit, 26-27 October 2011, Bento Goncalves, Brazil (eds. T. Yigitcanlar, A.C. Fachinelli), The World Capital Institute, Ibero-American Community for Knowledge Systems, pp. 128-136.

Harrison C., Eckman B., Hamilton R., HartswickP., Kalagnanam J., Paraszczak J., Williams P. (2010) Foundations for Smarter Cities. IBM Journal of Research and Development, vol. 54, no 4, pp. 350-365.

Hunt R., Xavier F. (2003) The leading edge in strategic QFD. International Journal of Quality \& Reliability Management, vol. 20, no 1, pp. 56-73.

Kanter R.M., Litow S.S. (2009) Informed and interconnected: A manifesto for smarter cities (GMU Working Paper no 09-141), Boston: Harvard Business School.

Keller R., Eckert C.M., Clarkson P.J. (2006) Matrices or node-link diagrams: Which visual representation is better for visualising connectivity models? Information Visualization, no 5, pp. 62-76.

Khromov-Borisov S. (2011) Upravlenie slozhnost'yu [Managing Complexity]. Strategicheskii menedzhment [Strategic Management], no 4, pp. 318-326 (in Russian).

Komninos N., Pallot M., Schaffers H. (2013) Open innovation towards smarter cities. Open innovation 2013, Luxembourg: European Commission, Directorate-General for Communications Networks Content and Technology, pp. 34-41.

Markets \& Markets (2016) Smart Cities Market by Solution and Services for Focus Areas (Transportation - Rail \& Road, Utilities - Energy, Water, \& Gas, Buildings - Commercial \& Residential, and Smart Citizen Services - Education, Healthcare, \& Security) - Global Forecast to 2020, Magarpatta: Markets \& Markets.

Monks K. (2015) CITE: The \$1 billion city that nobody calls home. Available at: http://edition.cnn.com/2015/10/06/business/test-city/index. html, accessed 14.02.2016.

Nordin R. (2012) Creating knowledge-based clusters through urban development: A study of Cyberjaya, MSC Malaysia (Doctoral thesis), Bonn: Rheinischen FriedrichWilhelms-Universität.

Paroutis S., Bennett M., Heracleous L. (2014) A strategic view on smart city technology: The case of IBM Smarter Cities during a recession. Technological Forecasting and Social Change, vol. 89, pp. 262-272.

Paskaleva K.A. (2009) Enabling the smart city: The progress of city e-governance in Europe. International Journal of Innovation and Regional Development, vol. 1, no 4, pp. 405-422.

Pentikousis K., Zhu D., Wang H. (2011) Network infrastructure at the crossroads the emergence of smart cities. Proceedings of the 15th International Conference "Intelligence in Next Generation Networks (ICIN)", Berlin: IEEE, pp. 109-114.

Portugali J. (2011) Complexity, Cognition and the City (Understanding Complex Systems), Berlin: Springer-Verlag.

Robinson R. (2015) Six Inconvenient Truths about Smart Cities. Available at: https://theurbantechnologist.com/2015/02/15/6-inconvenienttruths-about-smart-cities/, accessed 15.05.2016.

Robinson R. (2016) Why Smart Cities still aren't working for us after 20 years. And how we can fix them. Available at: https:// theurbantechnologist.com/2016/02/01/why-smart-cities-still-arent-working-for-us-after-20-years-and-how-we-can-fix-them/, accessed 15.05.2016.

Siegele L. (2012) Mining the urban data. Economist, 21.11.2012. Available at: http://www.economist.com/news/21566408-cities-willbecome-smarter-different-ways-many-people-expected-mining-urban-data, accessed 15.05.2016.

Singh K. (1997) The Impact of Technological Complexity and Interfirm Cooperation on Business Survival. The Academy of Management Journal, vol. 40, no 2, pp. 339-367.

Singh S. (2014) Smart Cities - A \$1.5 Trillion Market Opportunity. Forbes, 19.06.2014. Available at: http://www.forbes.com/sites/ sarwantsingh/2014/06/19/smart-cities-a-1-5-trillion-market-opportunity/\#3b9495237ef9, accessed 15.05.2016.

Sirkin H.L., Keenan P., Jackson A. (2005) The Hard Side of Change. Harvard Business Review, October issue. Available at: https://hbr. org/2005/10/the-hard-side-of-change-management, accessed 15.05.2016.

Townsend A., Maguire R., Liebhold M., Crawford M. (2010) The future of cities, information, and inclusion: A planet of civic laboratories, Palo Alto, CA: Institute for the Future.

Tsymbal S., Koptelov A. (2010) Intellektual'nye tekhnologii v teploenergetike [Intellectual technologies in heating]. EnergoRynok [Energy Market], no 4, pp. 57-59 (in Russian).

Tufte E.R. (2001) The Visual Display of Quantitative Information, Cheshire: Graphics Press.

UN (2015) The UNECE-ITU Smart Sustainable Cities Indicators, Vienna: United Nations. Available at: http://www.unece.org/fileadmin/ DAM/hlm/projects/SMART_CITIES/ECE_HBP_2015_4.pdf, дата обращения 17.05.2016.

UN (2016) Issues Paper on Smart Cities and Infrastructure, Vienna: United Nations. Available at: http://unctad.org/meetings/en/ SessionalDocuments/CSTD_2015_Issuespaper_Theme1_SmartCitiesandInfra_en.pdf, accessed 17.05.2016.

UNECE, ITU (2016) Rome Declaration (adopted by the participants of the Forum 'Shaping Smarter and More Sustainable Cities: Striving for Sustainable Development Goals', 19.05.2016, Rome, Italy). Available at: https://www.itu.int/en/ITU-T/Workshops-and-Seminars/

Documents/Forum-on-SSC-UNECE-ITU-18-19-May-2016/Rome-Declaration-19May2016.pdf, accessed 17.05.2016.

Vanolo A. (2014) Smart Mentality: The Smart City as Disciplinary Strategy. Urban Studies, vol. 51, no 5, pp. 883-898.

Washburn D., Sindhu U. (2010) Helping CIOs Understand "Smart City" Initiatives, Cambridge, MA: Forrester Research.

Weyrich P., Lind W. (2001) Twelve Anti-Transit Myths: A Conservative Critique, Washington, DC: Smart Growth America. 